\title{
Practical Interaction Design
}

\author{
Phil Turner \\ Centre for Interaction Design, School of \\ Computing \\ Napier University, Edinburgh \\ +44 (0) 1314552700 \\ p.turner@napier.ac.uk
}

\author{
Susan Turner \\ Centre for Interaction Design, School of \\ Computing \\ Napier University, Edinburgh \\ +44 (0) 1314552700 \\ s.turner@napier.ac.uk
}

\begin{abstract}
This paper describes a method for teaching interaction design in a school of computing setting. Practical Interaction Design is something of a hybrid incorporating elements of both 'pure' interaction design and human-computer interaction (HCI) to convey some of the flavour of the former with the tool-rich practicality of the latter.

Practical Interaction Design is distinguished from (traditional) HCI in many ways, but it is with respect to what it does not address that their differences are most pronounced. Practical Interaction Design is not explicitly user centred, there is no place for cognitive psychology per $s e$; nor for the modelling of tasks; nor for accounting for (that glaring category error) context. Instead there are roles for a Heideggerian treatment of familiarity; for ideation and for personae. The method itself incorporates a series of 'conversations' between designer and digital media and between designer and client.
\end{abstract}

\section{Categories and Subject Descriptors}

H.5.2 User Interfaces (D.2.2, H.1.2, I.3.6), Evaluation/methodology, Interaction styles

\section{General Terms}

Design, Human Factors.

\section{Keywords}

Human Computer Interaction, Interaction Design.

\section{INTRODUCTION}

Since its inception Human Computer Interaction (HCI) has been primarily concerned with designing interactive artefacts which are usable by specialist and non-specialist alike. It was quickly recognised that the best way to design usable, appropriate, effective and acceptable technology was to understand and involve people in the design process. This involvement has taken two forms. The first of these was to understand and model aspects of our psychology. For example, Card and his colleagues proposed a model of human cognition which could be used to guide the design of technology and to make predictions about its use [1]. This was the first of many attempts to capture, model, represent and employ accounts of human cognition [2, 3, 4]. However probably the greatest achievements in designing for relevant aspects of our cognition have been the creation of the graphical user interface (GUI); the desktop metaphor and the use of direct manipulation $[5,6,7]$. At approximately the same time as these psychological initiatives, efforts to involve end-users directly in the design process began. HCI adopted and developed user-centred design (UCD) approaches drawing upon English, Scandinavian and US practice $[8,9,10,11,12]$. The focus of UCD was to create interactive technology to automated aspects of a peoples' work. The rationale underpinning UCD is that the intended end-users are best placed to contribute their expertise on how they do their jobs (with a focus on the tasks they perform and the context in which perform them).

Involving people also has the added advantage of increasing the likelihood of 'user acceptance' of the resultant technology. Given this impetus, HCI rapidly emerged as a design discipline in its own right and with its growing maturity came both diversification and formalisation with the appearance of an ISO standard for human-centred development [12]. This brief historical sketch is intended to set the scene for and, in part, account for the ways in which HCI is taught. The major textbooks on HCI - $[13,14,15]$ all, in their different ways, recapitulate this historic development. And the way HCI is taught broadly follows the same pattern.

And then there was the Apple iPod ${ }^{\mathrm{TM}}$ and suddenly the world is changed. In many ways the iPod is emblematic of the latest generation of 'must have' interactive artefacts. The defining characteristic of the iPod is not its usability per se but its desirability and its design chic. The iPod; the Nintendo Wii and the Sony Aibo are typical of the new generation of interactive artefacts which are not (and as it will be argued, cannot be) the product of traditional HCI but of the emerging design discipline of interaction design.

There are number of definitions of interaction design (ID), many of which are too vague to be useful but Gillian Crampton Smith helpfully contributes the following "If I were to sum up interaction design in a sentence, I would say that its about shaping our everyday life through digital artefacts - for work, for play and for entertainment." [16, $p$. xi] Many regard this change in the design of interactive artefacts to be only one of emphasis, for example, the current title of the most widely selling HCI textbook is "Interaction 
Design: Beyond Human-Computer Interaction" [14]. The picture being further confused by practitioners and researchers who have broadened HCI's scope to include a number of other non-work perspectives (e.g. pleasure [17]; Fun [18]; aesthetic [19]; affect [20]). Specifically, Blythe and his colleagues note that their work reflects "... the move in human-computer interaction studies from standard usability concerns towards a wider set of problems to do with fun, enjoyment, aesthetics and the experience of use" [18]. In contrast, many interaction designers themselves believe that they have more in common with product or industrial design and consequently see interaction design as a (design) discipline in its own right $[16,21,22]$. Figure 1 is an illustration of how Moggridge (ibid) 'locates' interaction design in this context. To date these two different views have largely been a matter of (well informed) opinion.

So interaction design is about the design of digital artefacts which we not only use in our everyday lives but with which we co-exist. And it is this everyday co-existence which underpins the thinking of this module. There is a kind example, how many people must have, and must be seen to have, the latest technological offering from, say, Apple ${ }^{\mathrm{TM}}-$ witness the queues outside their stores at the launch of the latest mobile phone, music player or laptop? And how many people regard their mobile phone as being their most important possession, the loss of which is unthinkably traumatic?

All of this has profound consequences for how we think about, approach and most importantly teach HCI. Is it appropriate to teach the iPod-generation about task analysis or user-centred design when their world is filled with 'designer' consumer electronics? Indeed interaction design is also often described as 'designer-ly' placing a premium on the quality of the design itself. This design premium may be embodied in the brand and subsequently exploited.

The recognition that ID has the potential for shaping very many aspects of our everyday life is an important one but, of course, raises the questions 'how do we do it?' and 'how do we teach this?'.

\section{Physical design}

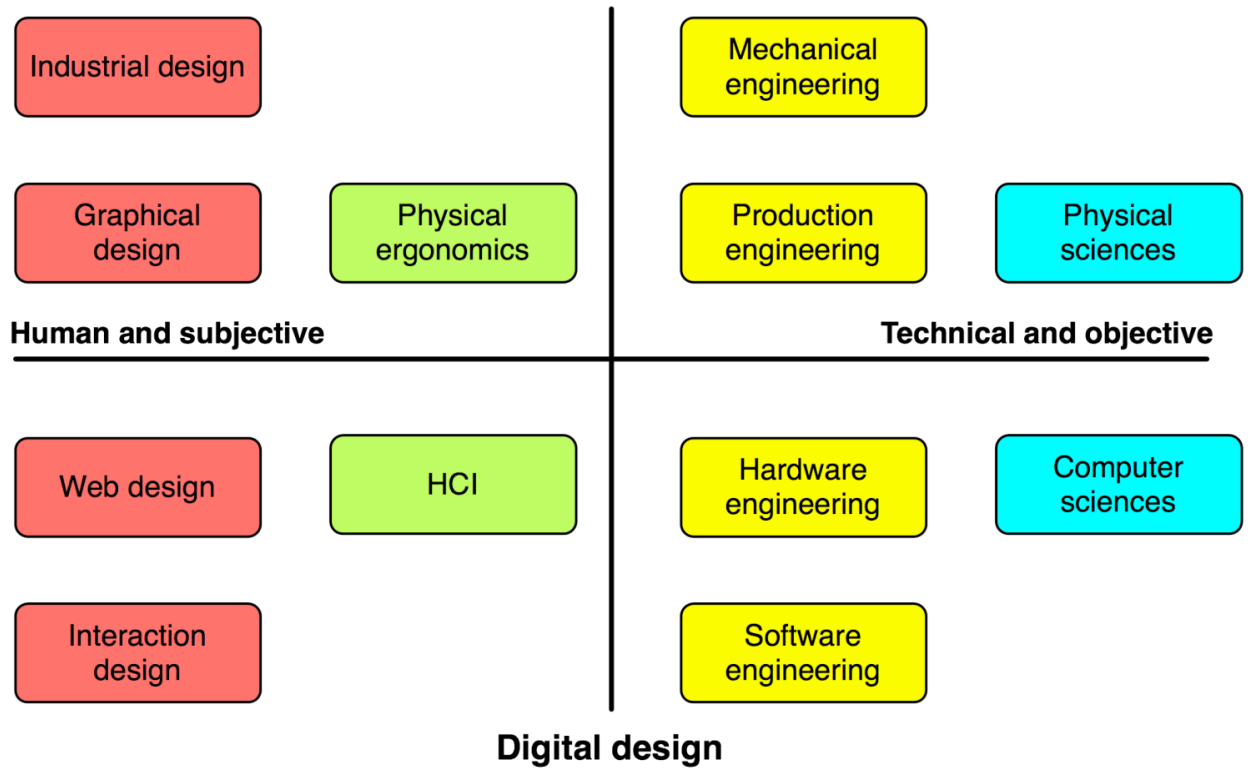

Figure 1: locating interaction design - redrawn after Moggridge, 2006

of parallel between this new generation of digital artefacts and the motor cars which might be useful to think about. Motor cars have been around for more than 100 years and began their existence as replacements for the horse and carriage (hence their earliest name - the 'horseless carriage'). They rapidly became utilitarian as evidenced by Ford's Model T. Now they have more to say something about our social status and wealth than they are a means of conveying us from A to B. Perhaps most importantly they are a technology without which we cannot live. The ways in which we have approached the design and development of interactive artefacts mirrors other technologies with interaction design being its 'post-modern' manifestation. Interactive artefacts are no longer purely instrumental. They are no longer purely utilitarian. Interactive artefacts are intended to be pleasurable to use, aesthetic in prospect and fun to own. This is design for so called Homo Ludens, for
Practical Interaction Design is a practical (sic) approach to the teaching of interaction design starting with the design brief, the designer's familiarity with the world ( $c f$. Heidegger), personae-based design, and really early prototyping which is treated as embodying the design. Thereafter, following Schön's conception of the design process [23], a series of conversations are conducted between the designer and the design (the digital artefact) and between the designer and the client. These conversations consider how to iteratively improve the design with respect to its target qualities - such as usability, accessibility, aesthetics and so forth. However before describing how this works in practice, interaction design and HCI will be contrasted in a little more detail. 


\section{HOW IS ID DIFFERENT FROM HCI?}

Design within Human-Computer Interaction has been traditionally user-centred, task-based and rationalistic. It emphasizes usability $[24,25,26]$ and user involvement [27, 28]. It is aims to match interactive technology with current working practice ('fitting the machine to the person'). It places a strong emphasis on understanding the user needs on new systems and the psychology - specifically, the cognition of those who will use it [2]. Its methods include formal modelling such as Goals-Operators-Methods-Selection GOMS [1], and the 'semi-formal' as the use of guidelines $[29,30]$. Carroll [31] in the introduction to his edited volume HCI Models, Theories and Frameworks notes that, "the initial vision of HCI [human computer interaction] as an applied science was to bring cognitive-science methods and theories to bear on software development. Most ambitiously, it was hoped that cognitive-science theory could provide substantive guidance at very early stages of the software development process." (p.3). What Carroll has described as the "golden age of HCI" saw this come to fruition.

\subsection{The HCI Lifecycle}

Figure 2 is a representation of the HCI lifecycle as defined by ISO 13407 standard on human-centred design. In many ways this lifecycle has a strong engineering feel to it. The un-

\subsection{User Centred Design}

The classic text on user centred design (UCD) is Norman and Draper's 1986 edited volume User Centered System Design [9]. In the introduction they describe the book as having originated from the editors' common interests of psychology and artificial intelligence (AI). The book was very much of its time with its contributors reading as a hall of fame of the best and the brightest in AI, cognitive science and humancomputer interaction. It is made clear that UCD (to adopt the more modern usage) necessarily involves many disciplines including "computer science, psychology, AI, linguistics, anthropology, and sociology - the cognitive sciences" (page 2 ) and that UCD is "about the design of computers, [ ... ] from the user's point of view" (ibid). In many ways it bears all the hallmarks of the Zeitgeist of the mid-1980's.

A user-centred design episode usually begins with the formation of the UCD team who will work in partnership with the intended end-users of the system to be built. The first task is a stakeholder analysis after which representative are recruited to work with the UCD team. The degree to which the users are involved varies from one 'flavour' of UCD to the next. These representative users help the designers define the requirements on the system or device by (and again these varies greatly) providing information on what the system will be used for, where it will be used, how

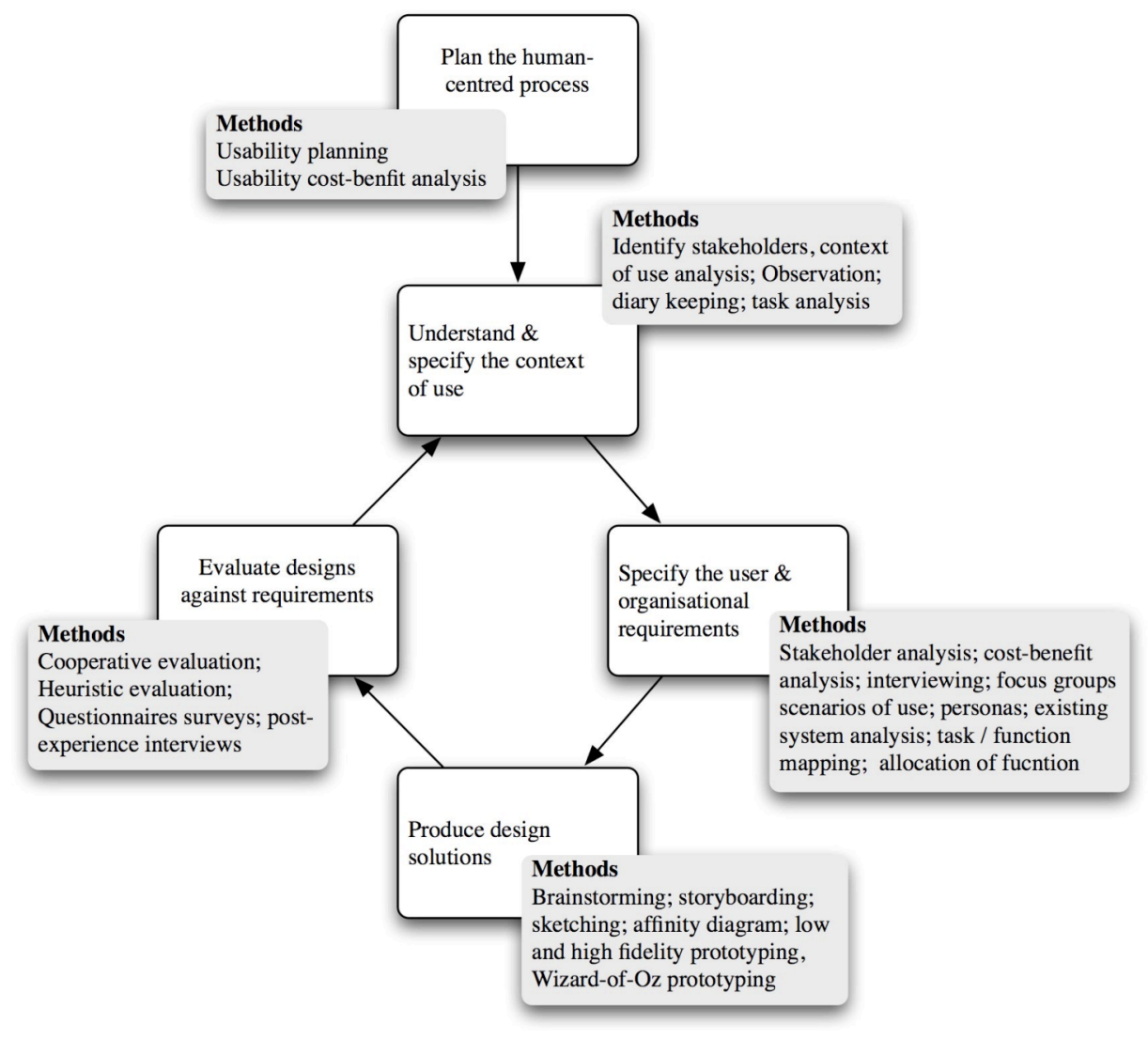

Figure 2: the HCI lifecycle (un-shaded) with tools and methods appearing in the shaded boxes

shaded boxes identify the steps in the process: the shaded boxes list some of the available methods. HCI has been successfully taught, practiced and research like this for a generation. often it will be used and so forth (e.g. 11, 32]). The volume of data collected then needs to be understood, harmonised (to remove inconsistencies), consolidated, prioritised and managed. Here we see design as a process of abstraction and compromise. They emphasized the importance of having a 
good understanding of the users (but without necessarily involving them actively in the process).

"... user-centred design emphasizes that the purpose of the system is to serve the user, not to use a specific technology, not to be an elegant piece of programming. The needs of the users should dominate the design of the interface, and the needs of the interface should dominate the design of the rest of the system."

$$
1986
$$

Norman,

\subsection{Task-Based}

The role of tasks in HCI is pivotal. For example, in developing interactive artefacts the focus of design should be on how to complement and extend human purposive activity. The origins of task analysis (and user involvement) lie with the aims of 'scientific management' which arose in the early twentieth century when mass production and the assembly lie began to appear.

Task-based design begins by identifying who is doing the work and what they do (what they actually do rather than what they claim to do) and identifying the requirements (a very software engineering term) on the new system which will enhance or complement the current situation. Experience has shown that user involvement in the design process improves the acceptance of the resultant technology and the quality of the fit between it and existing working practices. Tasks are typically modelled using a variety of notations both formal and informal - and are often directly used to sequence user actions at the user interface to the new technology or inform the design of, say, the menu or screen layout.

\subsection{Rationalistic}

Human-computer interaction involves rationalistic design which Winograd and Flores describe as the attempt to model people as "cognitive machines", whose psychology and behaviour can be built on or reproduced by computers [33]. Winograd [34] also notes that the clearest expression of this view is Newell and Simon's physical symbol system hypothesis [35] which in turn was a major influence in the first great HCI text - The Psychology of Human Computer Interaction [1]. Given this cognitive models and psychologically-plausible engineering models of human behaviour have subsequently been derived which, to a greater or lesser extent, have proved to be able to model the behaviour of people using interactive systems and devices [36]. Strongly predictive models such as the Keystroke-Level Model [37] have been used to predict the time to complete a task for a skilled individual. Perhaps the most famous is Fitts' law [38] which has been successfully used in a variety of setting and recently, for example, to predict text entry speed on mobile phone [39]. In addition to these predictive models are a range of tools such as GOMS which have been used in the design and evaluation of user interfaces to interactive systems [40]. So equipped the designer has been able to design and implement usable interactive systems.

\subsection{So How Is Interaction Design Different?}

First of all, as has already been noted there is clearly an overlap between HCI and ID depending upon who you read (or believe) but some important differences include:
- Interaction Design is driven by the designer / design team / and design brief rather than being user-centred;

- Interaction Design is concerned with creating digital artefacts rather than necessarily in response to particular problems. Innovation drove the creation of the iPhone and iPod rather than solving particular work related problems.

- Interaction design is not an engineering discipline; is not a branch of software development (see figure 1). Interaction Design is an art [41].

Figure 3 is a representation of the ID lifecycle with appears in Moggridge [16]. While some of the steps and language are familiar to the HCI practitioner and teacher the process is not. Nor is the setting. Interaction design is a studio-based discipline as found in schools of art and design rather than the labs and classrooms of schools of computing.

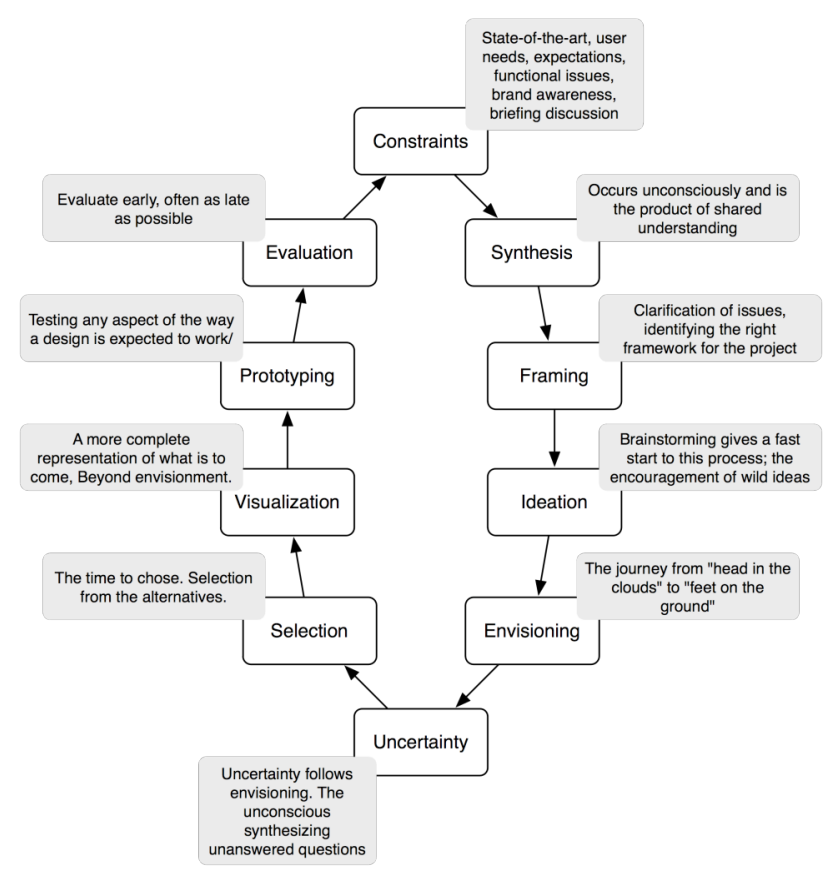

Figure 3: the Interaction Design lifecycle (re-drawn after Moggridge, 2006

If we are to meet the demands of the iPod-generation and respond to changes in how we design interactive media and technology we need to take on some of the flavour of interaction design and necessarily shed some less useful aspects of HCI.

What follows is a description of Practical Interaction Design: an approach which is something of a hybrid between 'pure' interaction design and human-computer interaction (HCI) drawing on elements of both to convey some of the flavour of the former with the tool-rich practicality of the latter. Each element of the approach is described together with illustrations of how it has been taught in the classroom and lab. The module concerned was taught through twelve 2 hour lectures and 2 sets of twelve 1 hour practical classes, each practical group being a maximum of 25 students. Both undergraduate (Scottish year 2) and postgraduate versions were delivered, the postgraduate versions incorporating stronger theoretical and critical emphases. 


\section{FOUNDATIONS}

The three key elements of Practical Interaction Design are:

1. The initial design based on the twin foundations of the designer's familiarity with the world and technology and the client's design brief. The designer works with a client to clarify and understand what he or she wants.

2. The profile of the people being designed for, expressed as personae.

3. Based on (1) and (2), the development of a very early prototype. Since, as argued above, it is inappropriate for this to be task-based it must therefore be affordancebased.

\subsection{The Design Brief}

This is the 'wild card' in the whole process as this can, potentially, be anything. It is emphasized in teaching that this may be as loosely defined as 'a new application for the iPhone' (the brief set for coursework in the first delivery of the Practical Interaction Design module) to a tightly specified set of requirements. The problem set by the brief may be practical or impractical, tractable or intractable, clearly defined or wishful thinking. The designer's task is to understand and ground whatever it is that the client wants using their familiarity with the world and the technology it comprises.

\subsection{Familiarity}

The world into which we were born is both filled with and defined by technology: technology with which we have been familiar from our earliest moments. Familiarity is a thorough knowledge of, or an intimacy with something or someone. The etymology of the word indicates that it is from the same root as family. Familiarity is commonplace and everyday, indeed we are warned that it breeds contempt and children (Mark Twain). Aside from familiarity as intimacy, it can also be used to indicate a passing acquaintance. For example, cabin crew routinely ask passengers to locate the emergency exits as they may not be familiar with the layout of that particular aircraft. Familiarity can also be thought of comprising (individual) tacit knowledge [42]. Tacit knowledge or 'know-how' involves learning and skills which cannot easily be quantified except through their articulation. Riding a bike, for example, is best learned through direct experience, by closely observing others, or being guided by an instructor. Familiarity is, thus, more than a just cognitive representation such as a mental model or other complex cognitive structure but may be better described as comportment - or orientation towards the world. Familiarity is also the means by which we make sense of artefacts. We necessarily make sense of the unfamiliar by relating it to the familiar. Interaction designers (and human-computer interaction specialists) working with digital media also recognize the need to ground their design efforts in the familiar. Traditionally metaphor and analogy have been used to convey a sense of the familiar, for example, the creators of the desktop metaphor assumed that people could make inferences about the behaviour of the computer-based desktop from their knowledge of real desktops. Indeed the use of metaphor in human computer interaction (HCI) is pervasive. Consider the ubiquity of actions and objects within HCI such as 'cut and paste' and references to web 'pages' and 'navigation' which rely on our familiarity with their real world referents.
Our familiarity with interactive technology facilitates our ability to cope with it and in coping with it we change, improve, modify our familiarity with it. Familiarity is not a static body of knowledge (which is implicit in the use of metaphor and analogy) but is adaptive. Our experience of coping with technology directly informs our familiarity with it and reciprocally our ability to cope.

Students are encouraged to draw on their familiarity with interactive technology to make sense of and to understand the design brief and to ground that understanding in what technology can and cannot do. Two classroom activities help to seed this process. An early tutorial comprises a 'show and tell' session where students present and discuss examples of 'good' and 'bad' everyday technology design: this helps to convince students they already have an intrinsic sense of what makes a design work. This is complemented by an informal classroom quiz probing knowledge of recent developments in interactive technologies, designed to illustrate the fact-moving pace of innovation and the need to keep oneself informed - or to maintain familiarity - with it. This phase of Practical Interaction Design culminates in the generation of first ideas for the design project - in the module as delivered, the iPhone application. Practical classes undertook a version of Method 635, as described in [43] in support of this activity.

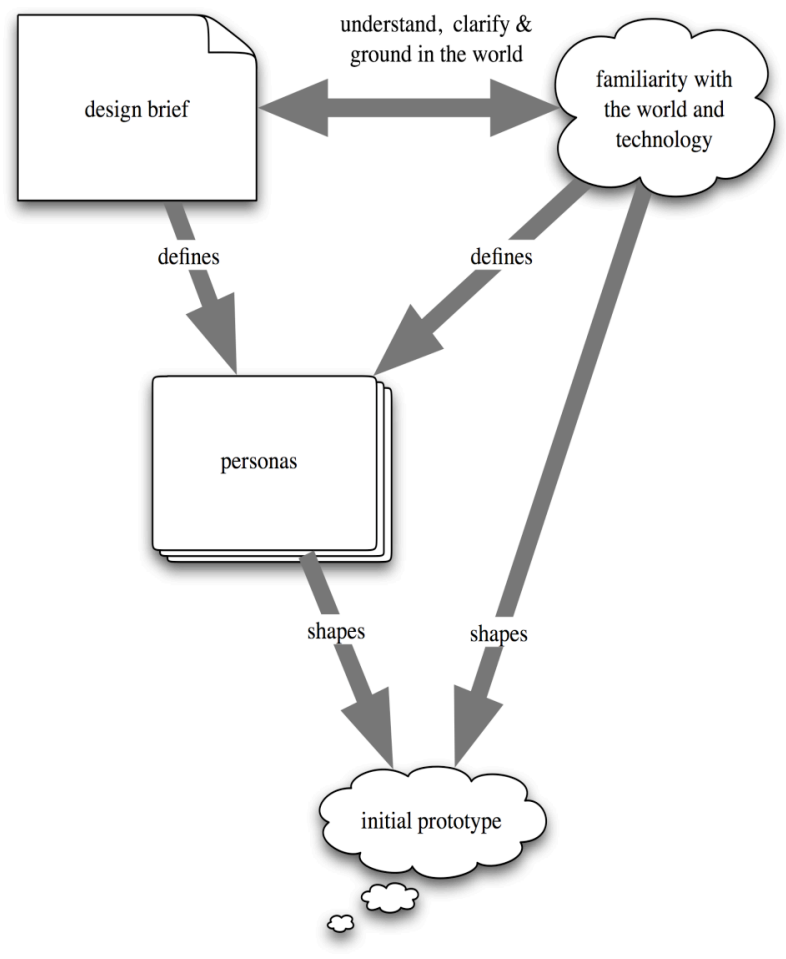

Figure 4: The Foundations of Practical Interaction Design

\subsection{Personae}

Having established an initial, informal understanding of what is to be designed it is now that who is being designed for is brought into consideration. Personae are introduced here, as lively, realistic, personalised embodiments of target users and their characteristics. Established HCI 'user' research techniques and the tools of design ethnography - the various 
flavours of interviews, observational methods and artefact collection - are taught as supporting activities for persona development. As students gather data and define a set of personae for their emerging design they are supported in the identification of design implications and the consequent modifications to the design concept. The project, however, remains design-led rather than user-driven. Further, the longestablished HCI tools of scenarios, detailed sketches and storyboards are held in abeyance until later.

\subsection{Prototyping and Affordance}

Turning these initial ideas into something tangible is the pivotal step in the whole Practical Interaction Design process. The sooner the designer commits something to paper or low fidelity software the sooner can the process of iterative refinement (or wholesale abandonment) begin. In practising Practical Interaction Design students start with paper prototypes and move on to embody their designs as simple software applications ${ }^{1}$. The aim is to create a prototype / design which embodies a first cut of the features created for the target persona. Crucially, these features are not defined as a response to 'user needs' or 'tasks' but as affordances offered to those who will interact with the artefact. Traditionally, HCI has approached the design of interaction with the unvoiced assumption that we issue commands (that is, click, type or touch) to which the technology responds, we respond to the response and so forth. The choice of command is determined on the basis of a (mental) representation the task. But if what we think about interaction as identifying and exploiting the affordances offered by the prototype or finished artefact? What might follow is a game-like, exploratory approach to interaction and one which is closer to the aims of interaction design. The affordances offered by the artefact are then iteratively refined through a series of 'conversations' (following [44]).

\section{CONVERSATIONS}

Building on these three foundational elements - an initial design, appropriate personae and an early prototype - the design is developed through a process of 'enlightened trial and error'. In Practical Interaction Design this first takes the form of a series of three conversations with the digital prototype:
1. is it easy to use?
2. is it accessible?
3. is it aesthetically pleasing?

The design of the artefact is modified and honed as a result of these dialogues and finally documented as the subject of a conversation with the client.

\subsection{Conversations with the Technology}

The subject of first in the trio of conversations is the familiar (to HCI specialists) process of usability evaluation. But since this is a designer-driven development, it is heuristic evaluation rather than user testing which is employed. It is emphasized that the emerging design is already usable, accessible and pleasing to some degree: the goal of this phase of the process is to determine and enhance these qualities.

\footnotetext{
${ }^{1}$ We use Microsoft ${ }^{\circledR}$ PowerPoint ${ }^{\mathrm{TM}}$, which is surprisingly flexible as a prototyping tool, readily accessible and relatively usable by students from a wide range of backgrounds.
}

Students evaluate each other's software prototypes against an established set of usability principles and with reference to (but not impersonating) the personae documented by the designer. We have found that the Ergonomic Guidelines For User-Interface Design from Cornell University Ergonomics Web [45] work well here, but there are of course many other equally applicable examples. A similar process interrogates the design, as appropriate, against accessibility guidelines. The final conversation concerns aesthetic appeal. The theoretical basis of the aesthetics of interactive technologies is a matter of some debate and well-documented means of evaluating aesthetic quality correspondingly rare. In this instance, the aesthetics conversation was informed by Jordan's Pleasure with Products instrument [17], but an adaptation of Desmet's Product Emotion Measure [46] would also have been suitable.

At the conclusion of this set of conversations a usable, accessible and aesthetically pleasing design has been defined. This can now be documented as the basis of a renewed conversation with the client - in this case the module tutors. It is in this conversation, rather than in the exploration of early design ideas, that scenarios, detailed sketches and storyboards come to the fore, together with the personae which have already been documented. Their role in Practical Interaction Design is thus as communication media.

\section{DOES IT WORK AND WHAT NEXT?}

In particular, the design-led approach has been found sympathetic by students with an art, design or media background, while others with a more technological bent have still found the process stimulating. For some international students and others less confident with relatively unconstrained design ideation, the initial stages proved more challenging, but support from tutors and peers helped to clear most initial hurdles. Finally, Practical Interaction Design has been feasible to teach in groups of around 25 rather than requiring a significant amount of small group studio-style teaching. However, a small-group 'Design Crit' session was include as a pivotal element in teaching: this is described below.

\subsection{Assessing Practical Interaction Design}

Pass-rates provide a further indication of the success of Practical Interaction Design with $25 \%$ of the students records marks of better than $70 \%$. Assessment was by coursework only. A first coursework required firstly, attendance at a 'Design Crit' session in week 10 of 12 with a tutor and 4-5 student peers. Students presented their iPhone application design and its rationale in no more than 5 slides, as if pitching to a client. The tutor - albeit slightly out of client role - probed claims as to usability, accessibility and fun/aesthetics/pleasure in relation to the main target persona. Student peers were instructed to - and did - provide constructive comment. Each student received individual written feedback. Coursework 1 subsequently required deliverables of a persona, a scenario and the prototype design implemented in PowerPoint. The results included ideas which were both innovative and creative, such as a boxing game which used the iPhone's accelerometer; a DJ mixing desk; a web-cam portal; and a reminder system for medication.

Coursework 2 was designed to build on concepts of the familiarity of everyday technology and expose students to one aspect of design ethnography. It comprised an auto- 
ethnography, specifically a 30-45 minute video diary, accompanied by a written commentary and analysis about the individual's own use of everyday interactive technology. This was perhaps less successful, primarily for reasons connected with the technology for delivering the diary, and some surprising (to the teaching team) unfamiliarity with the concept of a diary in itself. [47] (accepted for this workshop) provides for a full discussion of the auto-ethnography project.

\subsection{Future developments and conclusion}

Experience of this delivery suggests that paper prototyping does not engage all students convincingly and in the next delivery, simple sketching will be more prominent at this stage. As for the conversations, usability and accessibility would be better combined as one topic, while other conversations will be added - including, for example stylishness, legality, green credentials and support for cooperation or sharing.

In conclusion, the Practical Interaction Design model translates well into a module which the first author and colleagues have now successfully delivered. Teaching a model / module such as this should reveal any inconsistencies in underpinning reasoning or framing narrative: no such inconsistencies surfaced. The method made sense to teacher, teaching colleagues and students, whose feedback has been very positive.

\section{ACKNOWLEDGEMENTS}

We would like to thank our colleagues Colin Smith and Emilia Sobolewska for their contribution to the teaching of this module.

\section{REFERENCES}

[1] Card, S. K., Moran, T.P. and Newell, A. (1983) The Psychology of Human-Computer Interaction. Hillsdale, LEA, New Jersey.

[2] Gardiner, M.M. and Christie, B. (1987) Applying Cognitive Psychology To User-Interface Design. John Wiley \& Sons, Inc. New York, NY, USA

[3] Payne, S. J. (1991) A Descriptive Study Of Mental Models. Behaviour and Information Technology, 10, 321

[4] Carroll, J. M. (1996) Human Computer Interaction: Psychology As A Science Of Design. International Journal Of Human-Computer Studies, 46, 501-522.

[5] Bewley, W.L., Roberts, T.L., Schroit, D. and Verplank, W.L. (1983) Human Factors Testing In The Design Of Xerox's 8010 "Star" Office Workstation. Proceedings of the Conference on Computer Human Interaction 1983, $72-77$

[6] Schneiderman, B. (1983) Direct Manipulation: A Step Beyond Programming Languages. IEEE Computer, 16(8), 57-69.

[7] Smith, D. C. (1985) Origins of The Desktop Metaphor: A Brief History. Panel Presentation. The Desktop Metaphor as an Approach To User Interface Design. Proc. ACM Annual Conference, 548.
[8] Mumford, E. and Weir, M. (1979) Computer Systems and Work Design: The ETHICS Method, New York, Wiley \& Sons.

[9] Norman, D.A. and Draper, S.W. (1986) User Centered System Design. Hillsdale, NJ: Lawrence Erlbaum Associates.

[10] Bødker, S., Grønbæk, K., and Kyng, M. (1993) Cooperative Design: Techniques and Experiences From The Scandinavian Scene. In D. Schuler and A. Namioka (Eds.) Participatory Design: Perspectives On Systems Design. Hillsdale, New Jersey: Lawrence Erlbaum Associates, 157-175

[11] Beyer, H, and Holtzblatt, K. (1998) Contextual Design. San Francisco: Morgan Kaufmann.

[12] ISO (1999) ISO 13407: Human-Centred Design Processes For Interactive Systems. Geneva: International Standards Organisation. Available From The British Standards Institute, London.

[13] Schneiderman, B. (1998) Designing the User Interface. Addison Wesley Longman.

[14] Sharp, H., Rogers, Y. and Preece, J. (2007) Interaction Design: Beyond Human-Computer Interaction. John Wiley and Sons.

[15] Dix, A., Finlay, J., Abowd, G. and Beale, R. (1998) Human-Computer Interaction. Prentice Hall.

[16] Moggridge, W. (2007) Designing Interactions. MA: MIT Press.

[17] Jordan, P. (2000) Designing Pleasurable Products. Taylor Francis

[18] Blythe M.A., Monk A.F., Overbeeke K. and Wright, P.C. (2003) (Eds.) Funology: From Usability To Enjoyment. Kluwer Academic Publishers.

[19] Petersen, M.G., Iversen, O.S., Krogh, P.G. and Ludvigsen, M. (2004) Aesthetic Interaction: A Pragmatist's Aesthetics of Interactive Systems. Proceedings Of The Conference On Designing Interactive Systems, 269 - 276.

[20] Norman, D.A. (2004) Emotional Design. New York: Basic Books.

[21] Saffer, D. (2006) Designing for Interaction: Creating Smart Applications and Clever Devices. Peachpit Press

[22] Buxton, W. (2007) Sketching User Experiences: Getting The Design Right and The Right Design. Morgan Kaufmann.

[23] Schön, D. (1984) The Reflective Practitioner: How Professionals Think in Action. London, Temple Smith.

[24] Shackel, B. (1981). The concept of usability. In Proceedings of IBM Software and Information Usability Symposium, Poughkeepsie, NY, 15-18 September 1981, pp. 1-30.

[25] Shackel, B. (1986) Ergonomics in design for usability. Proceedings Of The Second Conference Of The British Computer Society, Human Computer Interaction Specialist Group On People And Computers: Designing For Usability, 44-64. 
[26] Eason, K. D. (1984) Towards the experimental study of usability. Behaviour and Information Technology, $\mathbf{3}$, 133-143.

[27] Damodaran, L., Simpson, A. \& Wilson, P. (1980) Designing Systems for People. Manchester: NCC National Computing Centre, pp. 25-31.

[28] Damodaran, L. (1996) User Involvement In The Systems Design Process: A Practical Guide For Users. Behaviour and Information Technology, 15, 262-377.

[29] Smith, S.L. and Mosier, J.N. (1986) Guidelines for Designing User Interface Software. Technical Report ESD-TR-86-278. The MITRE Corporation Bedford, Massachusetts, USA

[30] Hartson, D. and Hix, H.R. (1993) Developing User Interfaces. John Wiley and Sons.

[31] Carroll, J. M. (2003) Introduction: Towards A Multidisciplinary Science Of Human-Computer Interaction. In J. Carroll (Ed.) HCI Models, Theories and Frameworks. Morgan Kaufmann.

[32] Lim, K.H., Benbasat, I. and Todd, P.A. (1996) An Experimental Investigation of the Interactive Effects of Interface Style, Instructions, and Task Familiarity on User Performance. ACM Transactions on ComputerHuman Interaction, 3(1), 1-37.

[33] Winograd, T. and Flores, F. (1986) Understanding Computers and Cognition: A New Foundation for Design. Norwood NJ, Ablex.

[34] Winograd, T. (2006) Shifting Viewpoints: Artificial Intelligence and Human-Computer Interaction. Artificial Intelligence, 170, 1256-1258

[35] Newell, A. and Simon, H.A. (1976) Computer Science As Empirical Enquiry: Symbols and Search. Communications of ACM, 19(3), 113-126.

[36] Hollnagel, E. and Woods, D. (1983) Cognitive Systems Engineering: New Wine In New Bottles. International Journal Of Man Machine Studies, 18, 583-600.

[37] Card, S., Moran, T.P., and Newell, A. (1980) The Keystroke-Level Model for User Performance Time with Interactive Systems. Communications of the ACM, 23(7), 396-410.

[38] Fitts, P.M. (1954) The information capacity of the human motor system in controlling the amplitude of movement. Journal of Experimental Psychology, 47, 381-391.

[39] Silfverberg M., MacKenzie, I.S. and Korhonen, P. (2000) Predicting text entry speed on mobile phones. Proceedings of the SIGCHI conference on Human factors in computing systems. The Hague, The Netherlands, $9-16$.

[40] John, B.E. and Kieras, D.E. (1996) Using GOMS For User Interface Design and Evaluation: Which Technique? ACM Transactions On Human Computer Interaction, 3(4), 287-319.

[41] Norman, D. (2006) Interaction Design is still an Art Form. Ergonomics is a real engineering. interactions / January + February, p. $45 \& 60$.

[42] Polanyi, M. (1967) The Tacit Dimension. Routledge and Kegan Paul, London

[43] Löwgren, J. and Solterman, E. (2004) Thoughtful Interaction Design, MIT Press

[44] Schön, D.A. (1984) Problems, frames and perspectives on designing. Design Studies, 13(2), 135-156.

[45] Cornell University (2009) Ergonomic Guidelines For User-Interface Design http://ergo.human.cornell.edu/ahtutorials/interface.html, last accessed $20^{\text {th }}$ January 2009.

[46] Desmet, P.M.A. (2003). Measuring Emotion; Development and Application of an Instrument to Measure Emotional Responses to Products, In: Blythe, M.A., Monk, A.F., Overbeeke, K. and Wright, P.C. (eds), Funology: From Usability to Enjoyment, Dordrecht: Kluwer Academic Press, pp. 111-123.

[47] Sobolewska, E., Smith, C.F. and Turner, P. (2009) Auto-Ethnography: Problems, Pitfalls and Promise. To appear in proc. HCI-ED 2009. 